\title{
The Brain's "New" Science: Psychology, Neurophysiology, and Constraint
}

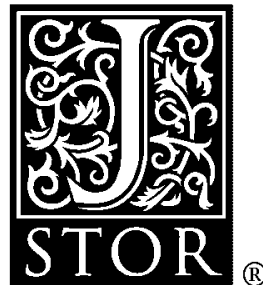

\section{Gary Hatfield}

Philosophy of Science, Vol. 67, Supplement. Proceedings of the 1998 Biennial Meetings of the Philosophy of Science Association. Part II: Symposia Papers (Sep., 2000), S388-S403.

Stable URL:

http://links.jstor.org/sici?sici=0031-8248\%28200009\%2967\%3CS388\%3ATB\%22SPN\%3E2.0.CO\%3B2-I

Philosophy of Science is currently published by The University of Chicago Press.

Your use of the JSTOR archive indicates your acceptance of JSTOR's Terms and Conditions of Use, available at http://www.jstor.org/about/terms.html. JSTOR's Terms and Conditions of Use provides, in part, that unless you have obtained prior permission, you may not download an entire issue of a journal or multiple copies of articles, and you may use content in the JSTOR archive only for your personal, non-commercial use.

Please contact the publisher regarding any further use of this work. Publisher contact information may be obtained at http://www.jstor.org/journals/ucpress.html.

Each copy of any part of a JSTOR transmission must contain the same copyright notice that appears on the screen or printed page of such transmission.

JSTOR is an independent not-for-profit organization dedicated to creating and preserving a digital archive of scholarly journals. For more information regarding JSTOR, please contact support@jstor.org. 


\title{
The Brain's "New” Science: Psychology, Neurophysiology, and Constraint
}

\author{
Gary Hatfield ${ }^{\dagger}$ \\ University of Pennsylvania
}

\begin{abstract}
There is a strong philosophical intuition that direct study of the brain can and will constrain the development of psychological theory. When this intuition is tested against case studies on the neurophysiology and psychology of perception and memory, it turns out that psychology has led the way toward knowledge of neurophysiology. An abstract argument is developed to show that psychology can and must lead the way in neuroscientific study of mental function. The opposing intuition is based on mainly weak arguments about the fundamentality or objectivity of physics or physiology in relation to psychology.
\end{abstract}

1. Introduction. Philosophers have long speculated about the strong constraints that brain science will or should provide for any future possible psychological theories. Hempel (1949) advocated replacing psychological language with physical language, which would be used to describe both behavior and brain states. Quine (1974) maintained that mentalistic talk could be tolerated in psychology only provisionally, as a means toward a full physiological or physical explanation of behavior. P. S. Churchland (1986) foresaw the replacement of "folk psychology" with neuroscientific descriptions. On the other side, Fodor (1974) has long plumped for the autonomy of psychology from neuroscience, by analogy with the (alleged) hardware-independence of computer programs.

These predictions of elimination or strong constraint were undertaken in virtually complete innocence of actual cases of interaction between scientific psychology and neurophysiology. Quine's discussions were simply so many promissory notes about the future course of science (Quine 1974, 33-34). Churchland's Neurophilosophy did not address genuine interactions between psychology and neuroscience, because the representative of

$\dagger$ Send requests for reprints to the author, Department of Philosophy, 433 Logan Hall, University of Pennsylvania, Philadelphia, PA 19104-6304.

Philosophy of Science, 67 (Proceedings) pp. S388-S403. 0031-8248/2000/67supp-0030\$0.00 Copyright 2000 by the Philosophy of Science Association. All rights reserved. 
psychology in that book was (philosophers') folk psychology, not the actual results of experimental psychology (see Corballis 1988, Hatfield 1988a). Further, Fodor's case for autonomy relied heavily on the computer metaphor (Fodor, 1975, Chs. 1-2), which turned out not to be the only game in town, and in any event he dismissed $(1975,17)$ the importance of physiology for psychology without engaging the living body of work in physiological psychology.

Contemporary philosophy of science seeks to understand the cognitive features of living science. Without aiming to be merely descriptive, it seeks to capture conceptual relations and explanatory structures that have a basis in actual scientific practice. In this article I appeal to real cases in support of the argument that, typically, psychological theory has led the way toward neuroscientific understanding. Section 2 surveys some major results in sensory psychology. Section 3 examines the strongest alleged case for the neuroscientific revision of fundamental psychological theory, the neurological finding of selectively preserved memory in amnesiacs. In Section 4, I offer a simple and straightforward conceptual argument that psychology must lead the way toward a neuroscientific understanding of mental function and the brain's role therein. These reflections and arguments raise the question of how it could have seemed so obvious to some philosophers that neuroscience must strongly condition or even replace psychology. Section 5 examines this question and asks what it means to say instead that psychology conditions neuroscience.

\section{Sensory Physiology: Psychology Leads and Constrains Neurophysiology.} Sensory physiology is an area of rich interaction between neuroscience and psychology, and one in which knowledge is well advanced in both domains. I consider the relation between psychology and neurophysiology in three historical cases that span the modern period. The earliest case serves as a reminder that a basic functional parsing of the body and nervous system is itself a fundamental achievement, and is by no means obvious. The three cases are binocular single vision, stereopsis, and opponent processes in color vision.

2.1. Newton and Binocular Single Vision. We have two eyes with overlapping fields of vision, which receive separate impressions from objects in the area of overlap, and yet we usually see such objects singly. Since antiquity, these facts have led visual theorists to speculate about how single vision is achieved (Wade 1987). Early theorists, including Galen (discussed in Siegel 1970, 59-62), Alhazen (Ibn al-Haytham), and Witelo (discussed in Hatfield and Epstein 1979), proposed a physiological unification of binocular stimulation in the optic chiasma (where the two optic nerves meet). But since the optic nerves separate at the chiasma and continue on 
to separate sides of the brain, a question remained about how the postchiasmally separate optic nerves mediate single vision (see, e.g., the figure in Discourse 5 of Descartes' Dioptric ([1637] 1958, 149).

Various early modern solutions were proposed, including Descartes' unification of binocular stimulation at the pineal gland (Descartes [1664] $1985,105)$. In the Queries to his Optics, Newton (1704) speculatively advanced the anatomical scheme that in fact underlies single vision. He proposed that nerve fibers from the two eyes "partially decussate"- that is, partially cross - in the optic chiasma, so that fibers from each hemifield of the retina join in the chiasma and proceed to their respective side of the brain in a manner that preserves retinotopic order. His reasoning was based on some erroneous comparative anatomy (he mistakenly believed that fish and chamelia lack a chiasma), but his functional conjecture was sound and was confirmed by observations on brain-damaged patients during the eighteenth century (Finger 1994, 83). One of the foremost findings in sensory physiology in the mid-twentieth century was the discovery, using single cell recording techniques in cats and primates, of neurons in the visual cortex that are activated only by input from both eyes (Barlow, Blakemore, and Pettigrew 1967; Poggio and Fischer 1977). Further, neurons receiving stimulation from one or both eyes are laid out retinotopically across the back of the brain (Barlow 1990). So Newton's anatomical conjecture is largely confirmed (although the neurons from each eye actually unite only cortically, and merely cross and become contiguous in the chiasma). Since only rudimentary anatomical knowledge of the brain was available in his time, with no techniques for examining neural microstructure, it is clear that Newton's understanding of the psychological function of single vision led the way to his neuroanatomical hypothesis.

2.2. Stereopsis. Our two eyes fixate the same objects from slightly different perspectives, which means that they each receive slightly different images of those objects. The disparities between the two images serve as a powerful source of information for the relative depth of the parts of objects or among objects. (Convergence, or the angles formed by the optical axes, serves as an independent source of information for absolute depth, via the geometry of angle-side-angle.) In the decades following the discovery of the stereoscope by Charles Wheatstone in the 1830s, P. L. Panum, A. W. Volkmann, W. Wundt, H. Helmholtz, and E. Hering, among others, investigated the psychophysics of the depth response (see Turner 1994, 13-26). They studied many features of the depth response, including acuity for disparity, the temporal course of the response, and the efficacy of crossed vs. uncrossed disparities (image elements reversed between the two eyes, or not). Although virtually nothing was known of the microphysiology of the brain, 
these investigators framed various speculative hypotheses about the anatomical and physiological basis of stereopsis.

When binocularly driven neurons were discovered in the 1960s, some of them showed sensitivity to varying degrees of disparity. Investigators immediately conjectured that these "disparity detectors" serve the binocular depth response (Barlow et al. 1967). In this case, a newly discovered anatomical structure and its physiological activity were interpreted in relation to a visual capacity whose properties had been discovered through psychophysical and psychological investigation alone. The precise psychological mechanism by which the detection of local retinal disparities produces a depth response remains unknown. But subsequent investigation has shown a deep interaction among neurophysiological work, computational simulation, and psychophysical studies. Bishop and Pettigrew, leaders in the neurophysiological and psychological study of stereopsis, conclude in their 1986 review of the field that individual neurophysiological results continue to be interpreted largely on the basis of psychophysical findings.

In a 1992 review, Tychsen found work on stereopsis had recently undergone a conceptual shift which he related to the neuroanatomical division of visual neurophysiology into parvocellular and magnocellular pathways. The pathways are named for types of cells found in layers in the lateral geniculate nucleus, which then project cortically. Parvocellular neurons are slow but finely tuned, magnocellular are fast and coarsely-tuned. Tyler (1990) applied these findings to binocular vision, distinguishing a fine, slow, global, foveal system that is good for static targets from a coarse, fast, local, wide-scope system, with greater sensitivity to moving targets. Although Tyler acknowledged that neuroanatomical studies provided "the inspiration for the psychophysical partition of sensory processing into categories of specialized analysis" (Tyler 1990, 1877), he also noted that he himself had previously (Tyler 1983) postulated similar multiple systems of stereopsis "on the basis of psychophysical evidence alone." In now linking psychological theories of stereopsis with neurophysiological findings, he hoped to facilitate testing "of proposed associations between the separable processes in the two domains" (Tyler 1990, 1894). Here there is linkage between neuroscience and psychology, but no precedence of brain facts over psychological facts. Indeed, the psychological facts about stereopsis again led the way.

2.3. Color Vision and Opponent Pathways. The golden age of visual science in the late nineteenth century saw two competing accounts of color vision (Turner 1994, Chs. 6-7). Helmholtz revived and extended Thomas Young's proposal that there are only three types of color sensitive elements in the retina, each responding maximally to a particular wavelength 
(Helmholtz [1867] 1925, 2: 134-146). Perceived color then results from the combination of stimulation from the three types of elements. In opposition to this simple trichromatic model of color vision, Hering argued that color vision results from three opponent processes in the central nervous system, one serving red-green perception, one blue-yellow, and one black-white (Hering 1875; Turner 1994, 130-134). Neither of these arguments was based on knowledge of retinal anatomy and microphysiology. Indeed, the photic properties of the cones, which are the retinal element subserving daytime color vision, were directly measured only in the latter part of the twentieth century (Kaiser and Boynton 1996, Ch. 5). Helmholtz's arguments were based on color matching experiments (on both normal and color-deficient observers), in which lights of known spectral composition are adjusted until they look the same. Hering's arguments were based on similar types of measurements, and on phenomenological observations. On phenomenal grounds, Hering contended that there are four color primaries: red, yellow, blue, and green. He argued that afterimages reveal adaptation effects among the four primaries, thereby revealing linkage in the underlying physiology: yellow produces a blue afterimage, red a green one, and so on. He also observed that color deficient individuals are always "red and green blind" (or "blue and yellow blind"), but are never simply "red blind" or "green blind." On these grounds he speculatively postulated yoked physiological process underlying red-green and blue-yellow perception, which operate in opponent fashion, so that a red sensation arises when the red-green channel is driven one direction, and a green sensation when it is driven in the opposite, or opponent, direction. In the 1950s Leo Hurvich and Dorothea Jameson revived the opponent process theory, arguing from psychophysical data obtained in certain kinds of color mixture experiments (cancellation experiments, reviewed in Hurvich 1981, Chs. 5-6). Subsequently, opponent neural mechanisms were discovered in the retina, lateral geniculate nucleus, and other brain loci. The theory that the three types of cone in normal human eyes are linked neurophysiologically into opponent processes is now widely accepted (Kaiser and Boynton 1996, Ch. 7).

In the three cases reviewed, psychophysics and phenomenology led the way to the postulation and subsequent confirmation of neural mechanisms. Which is not to say that researchers do not work the other way around, using specific neurophysiological findings to generate new research questions. Ken Nakamura (1990) contended that findings about brain anatomy called for some new psychological theorizing. Neurophysiologists had found that a larger portion of cerebral cortex is devoted to vision than had been thought, and that the areas are highly subdivided. He described this as a case in which, for once, "it is the physiologists who seem to be leading the way, at least as far as higher visual functions are 
concerned." In order to redress "this imbalance between psychology and neurophysiology," he offered a "speculative theory as to the overall functional organization of the visual system" (Nakamura 1990, 411). Physiology had shown the existence of apparently specialized areas, and psychology would now propose a functional organization for them, drawing on work from cognitive psychology, psychophysics, physiology, and artificial intelligence. Peter Kaiser and Robert Boynton, co-authors of the standard handbook on human color vision, allow that in work on color vision, findings from anatomy, neurophysiology, and photochemistry have sometimes inspired new psychophysical experiments, but they maintain that "the data of the psychophysicist, together with theories developed from such data, provide a framework within which the electrophysiologist conducts his research" (Kaiser and Boynton 1996, 26-27). Which suggests that while physiological facts and theories may inspire or confirm research and theory cast in psychological language, psychological language remains the primary vocabulary for describing the functions being investigated, including those investigated in neurophysiological research.

3. The Neuropsychology of Memory: H. M. Revisited. Standing in contrast to the finding of Section 2, Patricia Churchland $(1986,1996)$ has claimed that in some areas of work neurological results have led the way to a radical rethinking of basic theoretical categories in psychology. She makes the boldest claim for work in memory, declaring that "some data discovered by neuropsychologists are so remarkable, and so contrary to common assumptions, that they suggest that some basic assumptions about memory may be in need of radical revision" (Churchland 1986, 150). What are these basic assumptions? Are they merely the assumptions of "folk psychology," or does she mean the assumptions of scientific (experimental) psychology? Although "folk psychology" is her usual target, Churchland here addresses experimental psychology directly. She asserts that psychological theory on topics such as memory is in a "statu nascendi," its current level of development being "pretheoretical" (1986, 149, 153). But she found cause for hope. Studies of amnesiac patients led some neuropsychologists "to postulate two memory systems, each with its own physiological basis" $(1986,371)$. The two systems in question are the descriptive and procedural memories of Squire and Cohen 1984. As Churchland $(1986,372)$ tells it, their observations on amnesiac patients led them to posit distinct memory subsystems of a sort unlike those on offer from psychologists who study memory in the intact human.

The issue in question is not whether neurological observations are germane to psychological research on memory, but whether in this case neurological observation led to the introduction of new theoretical categories, and specifically, to the introduction of a novel distinction between descrip- 
tive and procedural memory systems. As it turns out, in Squire and Cohen's case (Cohen and Squire 1980, Squire and Cohen 1984, Cohen 1984) the theoretical framework they adopted was drawn from previous work in experimental psychology, cognitive science, and philosophy, as were the motivation for the empirical questions they asked and the experimental procedures they adopted.

The relevant part of Squire and Cohen's work concerned preserved learning and memory capacities in amnesiacs. The "preserved" capacities are those unaffected or only partially affected by the cause of the amnesia. It was well known that amnesiacs who suffer severe memory deficits may suffer no effects on perceptual-motor learning and memory (Milner, Corkin, and Teubner 1968). Squire and Cohen asked whether other sorts of skills are preserved. In Cohen and Squire 1980 they showed that amnesiac patients could perform well on a pattern-analyzing skill, which involved reading mirror-reversed words. Although the patients could not remember previous trials, even from day to day, their performance showed dramatic improvement over three consecutive days of testing and in a retest three months later. Cohen and Squire (1980) interpreted their results in relation to proposals made by Kolers (1975) and by Winograd (1975). Kolers (1975) used psychological experiments to study memory in intact adult humans. He interpreted his findings on sentence-recognition tasks (including tasks with geometrically reversed stimuli) by distinguishing between "operational or procedural" and "semantic or substantive" memory. Kolers drew this distinction from a discussion of "knowing how" vs. "knowing that" in a book on the philosophy of education by Israel Scheffler (1965), who in turn drew upon Gilbert Ryle's (1949) analysis of intelligent behavior. Winograd (1975) characterized the distinction between "knowing how" and "knowing that" as dividing procedural (programmed) from declarative (data base) knowledge. In a subsequent review and expansion of their results, Squire and Cohen $(1984,37)$ articulated their distinction, drawing directly on Ryle (1949), on work in psychology (Bruner 1969), and on artificial intelligence (including Winograd 1975). Finally, Cohen (1984) retested the much-studied amnesiac H. M. on a cognitive skill that had been well-studied by experimental psychologists, the "Tower of Hanoi" problem, and he further articulated the procedural-declarative distinction, again drawing on Ryle, Bruner, Kolers, Winograd, and other work in artificial intelligence.

In this case, the methods of testing, the framework for posing empirical questions, and the theoretical concepts used are drawn from previous work at a psychological or philosophical level of analysis. Moreover, Squire and Cohen $(1984,4)$ did not present their work as requiring revision of basic ideas about memory, but as a challenge to previous views on amnesia as a unitary phenomenon (an assumption they attributed to previous work 
in neurology). They presented themselves as developing and extending theoretical conceptions of memory and skilled performance extant in the psychological and philosophical literatures. Tests on various clinical populations provided a source of data about ways in which the normal functioning of human memory could be disrupted. Here, neurological results did not result in a fundamental rethinking of the basic categories of psychological theory, but in a refinement of those categories and an ability to relate them to brain loci known to be damaged in the amnesiac patients. This is "coevolution" of psychology and neuroscience as Churchland (1986) would have it, but with a genuine theoretical contribution coming from extant theoretical psychology, a contribution that Churchland missed in her portrayal of psychology as being in a "pretheoretical" state on these issues.

This case study does not show that reflection on neurological results, or on images or other recordings of brain activity, could not challenge the fundamental categories of psychological theory. Nonetheless, the image of neuroscience as arriving at its results independently of previous psychological theory invokes a naive Baconianism that is implausible. Experimental findings of the sort achieved by Squire and Cohen require posing questions to nature. This is true even if nature (or surgical procedures) have provided a "natural experiment" through a brain lesion. Subjects' performances are evaluated through systematic tests, not casual observation. Systematic experimental procedures are devised against a background of previous theory and previous experimental paradigms. Even casual observations are interpreted against a background of theory. In the case of psychological capacities such as learning and memory, it is natural to suppose that psychological theory will provide the background.

Again, this is not to say that neurological observation and neurophysiological measurement have not and will not continue to contribute to the advance of psychological theory. Indeed, subsequent work in memory has seen continuing interaction between psychological and neuroscientific research. The theoretical discussion has advanced to include alternatives to the "memory systems" approach favored by Squire (1987) and by experimental psychologists such as Tulving (1983). The alternative theory proposes that data from brain-damaged patients do not entail separate memory systems (despite the finding of a "double dissociation," which is often taken to imply distinct systems), because the data are also consistent with the hypothesis that various processing stages have been disrupted (Roediger, Srinivas, and Weldon 1989). Data from animal studies, clinical observations, and experiments on normal children and adults are all used in testing theories about the psychology of memory and its neurophysiological substrate (see, e.g., Foster and Jelicic 1999). Neuroscience has not provided an independent source of theory, but an additional source of 
data about function and about brain localization. That is a real contribution. But, as we shall see in Section 4, it is unclear that neuroscientific data provide any firmer constraint on psychological theory than do other kinds of data.

4. The Brain as a Mental Organ. Review of some central cases from psychological science and neuroscience shows that psychology has led the way in the study of the brain, at least so far. At the same time, bottom-up studies of nervous systems and brains have been revolutionized during the twentieth century, as a result of new staining, recording, and scanning techniques. The neuron doctrine, the discovery and classification of neural transmitters, and the advent of brain imagery stand as real and independent contributions of neuroscience.

Given the rapid advances in brain science during the twentieth century, one might conjecture that the leading role played by psychology in my case studies was the product of the different growth rates of psychological and specifically neuroscientific knowledge. Knowledge of the microstructure of brain tissue and measurement of neural activity required the development of microscopic techniques and technology for recording and, subsequently, imaging brain activity. The technology that made these results possible is less than a century old, and the more sophisticated techniques have arisen only in the past two decades. By contrast, psychology, at least at the beginning, could operate with less equipment. It could get started taxonomizing psychological function on the basis of data available through observation of everyday experience or behavior. One might think that its descriptions served well in an instrumentally simpler day, before the advent of techniques that made possible a direct assault on the brain. But in these auspicious times one might expect, with Quine and Churchland, that as science advances psychology will wither and neuroscientific concepts will replace its mentalistic descriptions.

While granting the great advances in the direct study of the brain's properties, I reject this line of reasoning. I think an argument is available to show that psychology must provide the functional vocabulary for describing much of the brain's activity. To understand the brain we must come to understand not only its microanatomy and microphysiology, but its global functioning. Some of its global functions serve to control vegetative functions, such as breathing or digestion. But the brain is most famous for its role in realizing mental functions, including sense perception, memory, emotions, and higher cognitive abilities. The description of these functions is mentalistic. This mentalism does not restrict itself to a statically traditional vocabulary - the "folk psychology" of neurophilosophical lore - but it avails itself of the developing technical vocabulary of psychological science. For example, as sensory psychology progressed, 
the traditional "sense of touch" was partitioned into numerous sensory systems (for haptic form, pressure, temperature, and more), thereby overturning the tradition of the "five senses" (Scheerer 1995, 825, 851-856). In this case, a traditional classification was overturned as psychology advanced. Still, as sensory psychology has developed into a mature science its language has remained mentalistic, including talk of information, representation, experienced qualities, perceived intensities, and so forth. Similarly, the language of attention research, while it has grown more precise, shows continuity with centuries of reflection on the phenomena of attention, mentalistically described (Hatfield 1998). The mentalistic language of psychology should not be equated with outdated tradition. It is a living vocabulary. And it is the vocabulary for describing global brain function. The brain is a mental organ.

These considerations provide the basis for a relatively straightforward argument to the effect that psychology must provide the primary theoretical vocabulary for describing many brain functions. The argument goes as follows:

(1) The operations of the brain can be partitioned into various subsystems, study of which constitutes study of brain function.

(2) Some of the functions realized by the brain are mental functions (e.g., perception, attention, memory, emotions).

(3) Psychology is the experimental science that directly studies mental functions.

(4) Hence psychology is the primary discipline covering a major subset of brain functions.

(5) Although it may be possible on occasion to reason from structure to function, in general knowledge or conjecture about function guides investigation of structure.

(6) And so psychology leads the way in brain science.

The premises have various bases, some tending toward the conceptual, some hinting at the empirical. But as in any conceptual argument about science, all of the premises have an empirical component. (1) records the fact that the brain is a complex system with identifiable subsystems, the operations of which can be usefully studied in relative independence of the other subsystems. (2) is a descriptive fact about the functions known to be realized by the brain. While it may seem bald and contentious, it is supported by reflection on the practice of brain science. Consult, for instance, the major and minor subdivisions of standard textbooks in neuroscience (e.g., Kandel et al. 1991). Neuroscientists use a psychological taxonomy to describe brain systems. They parse its operation into sensory, motivational, and motor systems (Kandel et al. 1991, Pt. IV, Ch. 19), which are further subdivided into areas such as sensation and perception, 
motor and motivational processes, language, and thought (Pts. V-IX). (3) comes as close to a conceptual truth as any. Psychology just is the science that studies mental functions in their own right. The only way to "eliminate" psychology from any foreseeable neuroscience would be simply to declare that theories of mental brain functions will now be called neuroscientific rather than psychological. (4) follows from (1)-(3). (5) is supported by reflection on the history of biological science and by the cases reviewed in Sections 2-3. It records the fact that typically, knowledge or conjecture about function guides the investigation of structure. Structure is hard to see in the absence of functional description. (5) blocks the supposition that a neuroscience devoid of psychological content could frequently provide a "bottom-up" route to discovering global brain function. (6) follows from (4) and (5).

5. Constraint. Suppose for the moment that this argument is correct. What implications does it have for the deeply held intuition that neuroscience is more basic than, and strongly conditions, psychology?

One could argue that psychology leads neuroscience only because of the epistemic limitations of the investigators. Because we start from a position of ignorance, we need to move from function to structure. But once we come to understand brain structure, we will see how it limits brain function. This position is in fact intuitively plausible. But to understand its import we should consider further the notion of constraint.

How does knowledge of one science constrain another? Once one understands chemistry, it becomes apparent that you cannot make water from carbon and nitrogen. The constituents constrain what can be done, or made, with them. Perhaps adequate knowledge of the brain would constrain psychology in the same way.

This I think is the model of constraint implicit in the intuition that neuroscience must constrain psychology. At a very general level, we can suppose that some constraint of this sort is known to us. We perhaps can be said to know that the nervous system of an earthworm is incapable of supporting philosophical reflection. Given the worm's ganglia, we see that it is unable to do philosophy; there are not enough circuits to permit deep reflection. (In fact our belief here is largely guided by knowledge of earthworm behavior in relation to its ganglia, but let us ignore this for the sake of argument.) Beyond extreme and very general instances such as this, so little is known about how brains realize psychological states and processes that this sort of constraint from constituent structure has no consequences for practice, now or in the foreseeable future.

A related intuition behind the idea that neuroscience constrains psychology is that physics is the basic science of what there is, and neuroscience is closer to physics than is psychology. Because physics is basic, it 
sets boundaries on what is possible. As a practical matter, this argument falls prey to the observation that in the present state of knowledge we have little or no idea about how physical properties limit the psychological properties that material objects, and brains in particular, can realize.

Still, the basicality of physics might be expressed through the notion of nomic asymmetry. It may be asserted as self-evident that psychology cannot postulate processes that violate the laws of physics, whereas physics is unconstrained by psychology. But in our present state of knowledge, this claim simply does not hold. Consider an example. Let us suppose that physics precludes psychology from positing processes in which information is transmitted from one location to another so that it arrives faster than the speed of light. We have been conditioned to nod assent to this. But should we treat this restriction as apodictic? Is it inconceivable that a psychological finding could cause us to question this statement? I think not. Conceive this. Under tightly controlled conditions, someone on earth is able to repeat what someone on the moon is thinking, and to do so with a time difference less than the time required for light to travel from the moon to earth. Teams of experts verify the empirical finding. Billionaires get interested in the phenomenon, and they hire the best scientists, physicists included, to monitor the test. It is concluded that the test is fair. What shall we do now? Posit the existence of extraphysical information transmission? Or consider revising the speed-of-light limitation on physical transfers? The latter option would seem to be open. So in this case, psychological facts might call physical theories in question. More generally, if facts are facts and truth is truth, it strikes me that physical facts, and true physical theories, cannot conflict with psychological facts and true psychological theories any more than the latter can conflict with the former.

The effective upshot of the basicality assumption is an abstract ontological asymmetry between physics and psychology. You can have physical things with no psychological properties, but we believe that nothing with psychological properties can fail to be realized in matter. You cannot have psychological properties in the absence of physical realization. This abstract constraint is far removed from theorizing about the actual psychological capacities realized in the brain, and from determining their relations to brain structures.

There are two additional, closely related intuitions that may help explain widespread assent to the notion that neuroscience is privileged over, and does or will control, psychology. The first is publicity: the brain is a physical object in the public domain. But an important area of psychology, the psychology of perception, concerns private objects, in the form of sensory experiences. So psychology is methodologically suspect. "Objective" knowledge is only of what is public. 
This argument is interesting in the abstract, but it runs afoul of actual scientific achievement. The first areas of psychology to be made objective, in the sense of achieving repeatable quantitative results, were sensory perception and psychophysics (Hearnshaw 1987, Ch. 9). A plausible description of the subject matter of psychophysics is that it charts the relations between physical stimuli and perceptual experience, as in the case of the trichromacy matching results achieved in the nineteenth century. The right hand term of laws in psychophysics, then, is the content of a mental state, the content of perceptual experience (see Shapiro 1995). So the much touted "privacy" of psychological states, whatever interest it might have, has not blocked the scientific study of such states.

The second intuition concerns an alleged contrast in empirical rigor between physics and psychology. Allegedly, physics is hard and objective, psychology is soft and subjective. According to Quine $(1974,36)$, psychological notions thrive in darkness, and they will dissipate when physics, or neuroscience, turns on the light. This argument relies on an inaccurate portrayal of the achievements of psychology. Typically, it relies on the construal of psychology as "folk psychology," that is, as a codification of (allegedly) ordinary ascriptions of beliefs and desires to explain behavior. But, as suggested above, the mentalistic vocabulary of psychology is a living body of scientific description. If it is to be challenged, it must be challenged on its own terms, and not, as often happens, by surreptitiously changing the subject so as to substitute so-called "folk psychology" for the corpus of scientific psychology. (On this point see also Hatfield 1988b, Wilkes 1980.)

Let us consider briefly some ways in which psychology conditions and constrains brain science. Primarily, psychology provides the basic functional description of numerous brain systems. This means that epistemically and methodologically psychology must lead the way in the study of global brain function. Ontologically, psychology may be seen as providing another constraint on brain structure. Brain structures presumably have evolved so as to realize advantageous psychological functions. For example, trichromatic color systems allow finer discrimination of objects by color than do dichromatic systems. The neural structures underlying trichromacy presumably exist in populations because of the psychological function they perform (Thompson 1995, Ch. 4). If this is so, then the ontology of the brain is affected diachronically, through selection for advantageous psychological functions. In this way, psychological function constrains brain ontology. (See Hatfield 1999 for further discussion.)

6. Conclusion. Reflection on neuroscience and psychology suggests that psychology has and must condition and constrain neuroscience. In the area of sensory perception, knowledge of psychological function has led 
the way in the individuation and investigation of visual neurophysiology. In neuropsychological investigation of memory, psychological theories of memory provided the framework within which questions were posed in the study of deficits caused by brain damage.

The idea that neuroscience can or should deeply constrain psychology is based on two sorts of arguments. First, there are abstract arguments concerning publicity, mushiness, nomic asymmetry, and ontological asymmetry. The first three sorts of argument are unconvincing. Ontological asymmetry provides a general constraint on solutions to the mind-body problem. But it does not offer real guidance for contemporary psychology.

The second sort of argument, from constituent structure, is based on the hope that future understanding of the brain will permit strong constraints to be "read off" descriptions of neural structure and activity. At present, constraints of this sort are at best very general, such as that earthworms cannot do philosophy. We can hope that knowledge of the brain's properties will progress to the point where this sort of constraint from constituent elements becomes available. One thing is for sure. If brain science does develop to that extent, psychology will lead the way.

\section{REFERENCES}

Barlow, Horace B. (1990), "What Does the Brain See? How Does It Understand?", in H. Barlow, C. Blakemore, and M. Weston-Smith (eds.), Images and Understanding. Cambridge: Cambridge University Press, 5-25.

Barlow, Horace B., Colin Blakemore, and J. D. Pettigrew (1967), "The Neural Mechanism of Binocular Depth Discrimination", Journal of Physiology 193: 327-342.

Bishop, P. O. and J. D. Pettigrew (1986), "Neural Mechanisms of Binocular Vision", Vision Research 26: 1587-1600.

Bruner, Jerome S. (1969), "Modalities of Memory", in G. A. Talland and N. C. Waugh (eds.), The Pathology of Memory. New York: Academic Press, 253-259.

Churchland, Patricia S. (1986), Neurophilosophy: Toward a Unified Science of the MindBrain. Cambridge, MA: MIT Press.

- (1996), "Toward a Neurobiology of the Mind", in R. Llinas and P. S. Churchland (eds.), The Mind-Brain Continuum: Sensory Processes. Cambridge, MA: MIT Press, 281-303.

Cohen, Neal J. (1984), "Preserved Learning Capacity in Amnesia: Evidence for Multiple Memory Systems”, in L. R. Squire and N. Butters (eds.), Neuropsychology of Memory. New York: Guilford Press, 83-103.

Cohen, Neal J. and Larry R. Squire (1980), "Preserved Learning and Retention of PatternAnalyzing Skill in Amnesia: Dissociation of Knowing How and Knowing That", Science 210: 207-210.

Corballis, Michael C. (1988), "Psychology's Place in the Science of the Mind/Brain?", Biology and Philosophy 3: 363-373.

Descartes, René ([1637] 1958), Dioptric, selections, in Descartes: Philosophical Writings. Translated by Norman Kemp Smith. Originally published as La dioptrique (Leiden: I. Maire). New York: Modern Library, 145-159.

-. ([1664] 1985), Treatise on Man, selections, in Philosophical Writings of Descartes, Volume One. Translated by J. Cottingham, R. Stoothoff, and D. Murdoch. Originally published as L'Homme de René Descartes (Paris: Girard). Cambridge: Cambridge University Press, 99-108.

Finger, Stanley (1994), Origins of Neuroscience. New York: Oxford University Press. 
Fodor, Jerry A. (1974), "Special Sciences, or The Disunity of Science as a Working Hypothesis", Synthese 28: 97-115.

- (1975), Language of Thought. New York: Crowell.

Foster, Jonathan K. and Marko Jelicic (eds.) (1999), Memory: Systems, Processes, or Function? Oxford: Oxford University Press.

Hatfield, Gary (1988a), "Neuro-Philosophy Meets Psychology: Reduction, Autonomy, and Physiological Constraints", Cognitive Neuropsychology 5: 723-746.

. (1988b), "Representation and Content in Some (Actual) Theories of Perception", Studies in History and Philosophy of Science 19: 175-214.

_ . (1998), "Attention in Early Scientific Psychology", in R. D. Wright (ed.), Visual Attention. New York: Oxford University Press, 3-25.

- (1999), "Mental Functions as Constraints on Neurophysiology: Biology and Psychology of Vision", in V. Hardcastle (ed.), Psychology Meets Biology: Conjectures, Connections, Constraints. Cambridge, MA: MIT Press, 251-271.

Hatfield, Gary and William Epstein (1979), "The Sensory Core and the Medieval Foundations of Early Modern Perceptual Theory", Isis 70: 363-384.

Hearnshaw, L. S. (1987), The Shaping of Modern Psychology. London: Routledge \& Kegan Paul.

Helmholtz, Hermann ([1867] 1925),. Treatise on Physiological Optics, 3 vols. Translated from the third German edition by J. P. C. Southall. The third German edition reprints the original first edition, Handbuch der physiologischen Optik (Leipzig: Voss). Milwaukee: Optical Society of America.

Hempel, Carl G. (1949), "The Logical Analysis of Psychology", in H. Feigl and W. Sellars (eds.), Readings in Philosophical Analysis. New York: Appleton-Century-Crofts, 373-384.

Hering, Ewald (1875), "Zur Lehre vom Lichtsinne, VI. Grundzüge einer Theorie des Farbensinnes", Sitzungsberichte der Kaiserlichen Akademie der Wissenschaften in Wien. Mathematisch-naturwissenschaftliche Classe, Pt. 3, 70: 169-204.

Hurvich, Leo (1981), Color Vision. Sunderland, MA: Sinauer Associates.

Kaiser, P. K. and R. M. Boynton (1996), Human Color Vision, 2nd ed. Washington, D.C.: Optical Society of America.

Kandel, E. R., J. H. Schwartz, and T. M. Jessell (1991), Principles of Neural Science, 3rd ed. Norwalk, CN.: Appleton \& Lange.

Kolers, Paul A. (1975), "Specificity of Operations in Sentence Recognition", Cognitive Psychology 7: 289-306.

Milner, Brenda, Suzanne Corkin, and H.-L. Teubner (1968), "Further Analysis of the Hippocampal Amnesic Syndrome: 14-Year Follow-Up Study of H. M.", Neuropsychologia 6: 215-234.

Nakamura, K. (1990), "The Iconic Bottleneck and the Tenuous Link between Early Visual Processing and Perception", in C. Blakemore (ed.), Vision: Coding and Efficiency. Cambridge: Cambridge University Press, 411-422.

Newton, Isaac (1704), Opticks. London: Sam. Smith and Benj. Walford.

Poggio, G. F. and B. Fischer (1977), "Binocular Interaction and Depth Sensitivity in Striate and Prestriate Cortex of Behaving Rhesus Monkey", Journal of Neurophysiology 40: $1392-1405$.

Quine, W. V. (1974), The Roots of Reference. La Salle, IL: Open Court.

Roediger, Henry L., Kavitha Srinivas, and Mary Susan Weldon (1989), "Dissociations between Implicit Measures of Retention", in S. Lewandowsky, J. C. Dunn, and K. Kirsner (eds.), Implicit Memory: Theoretical Issues. Hillsdale, NJ: Lawrence Erlbaum, 67-84.

Ryle, Gilbert (1949), The Concept of Mind. London: Hutchinson.

Scheerer, Eckart (1995), "Die Sinne", in J. Ritter and K. Gründer (eds.), Historisches Wörterbuch der Philosophie, Band 9:Se-Sp. Basel: Schwabe, 824-869.

Scheffler, Israel (1965), Conditions of Knowledge. Chicago: Scott, Foresman and Company.

Shapiro, Lawrence A. (1995), "What is Psychophysics?", in D. Hull, M. Forbes, and R. M. Burian (eds.), PSA 1994, Volume Two: Symposia and Invited Papers. East Lansing, MI: Philosophy of Science Association, 47-57.

Siegel, R. E. (1970), Galen on Sense Perception. Basel: S. Karger. 
Squire, Larry R. (1987), Memory and Brain. New York: Oxford University Press.

Squire, Larry R. and Neal J. Cohen (1984), "Human Memory and Amnesia", in G. Lynch, J. L. McGaugh, and N. M. Weinberger (eds.), Neurobiology of Memory. New York: Guilford Press, 3-64.

Thompson, Evan (1995), Colour Vision. London: Routledge.

Tulving, Endel (1983), Elements of Episodic Memory. Oxford: Oxford University Press.

Turner, R. Steven (1994), In the Eye's Mind: Vision and the Helmholtz-Hering Controversy. Princeton: Princeton University Press.

Tychsen, L. (1992), "Binocular Vision", in W. M. Hart (ed.), Adler's Physiology of the Eye. St. Louis: Mosby, 773-853.

Tyler, C. W. (1983), "Sensory Processing of Binocular Disparity", in C. M. Schor and K. J. Ciuffreda (eds.), Vergence Eye Movements: Basic and Clinical Aspects. Boston: Butterworths, 199-295.

. (1990), "A Stereoscopic View of Visual Processing Streams", Vision Research 30: $1877-1895$.

Wade, Nicholas J. (1987), "On the Late Invention of the Stereoscope", Perception 16: 785-818.

Wilkes, Kathleen V. (1980), "More Brain Lesions," Philosophy 55: 455-470.

Winograd, Terry (1975), "Frame Representations and the Declarative-Procedural Controversy", in D. G. Bobrow and A. Collins (eds.), Representation and Understanding: Studies in Cognitive Science. New York: Academic Press, 185-210. 